\title{
INFORMATION TECHNOLOGIES AS A SERVICE AND ADDICTION
}

\author{
Mefail Tahiri $^{*}$ Ejup Rustemi $^{2}$ \\ ${ }^{1}$ University of Tetova, North Macedonia \\ ${ }^{2}$ University of Tetova, North Macedonia \\ *mefailt@gmail.com
}

\begin{abstract}
We can hardly imagine someone without a technological device in their pocket, car, home or school. It is what makes us do things important for our life and work. Computer devices are so deeply attached to our daily lives that when we do have a cell phone or laptop near us, we seem to lose our minds. Any lack of internet will automatically make us unable to do anything and will make us think of whether there was a time when such things didn't exist?! What we try to explain in this paper is the issue of how can a tool made to help us do things better and faster can lead to addiction so deep that in turns into obsession and can have serious negative effect on our daily lives, therefore making these technologies a double-bladed sword.one important aspect regarding this is finding certain patterns that when followed we can have a clearer view on why information technology can turn from a helping hand into a time-wasting machine? It is important to notice here that we don't believe it to be a black and white issue, where a given person uses the tool to do his working routine, and by needing more and more information he gets so involved in its use that it becomes hard to get away from it. We think that there are some gray aspects in this case, we believe that the companies that produce these devices are helping in the way to making people addicted to these tools. Each one of the companies, especially those that sell mobile phones, continuously emphasize social network related aspects when they try to sell their devices; they always mention about ways you can stay connected with your loved ones such as family members and friends, thus making us think that without those devices we may lose connecting with those people. Yes, this is true to a certain degree, these devices do help people stay connected, but in order to communicate with our loved ones we shouldn't be entirely dependent on such things. This is the main aspect that we deal in this paper, in trying to shed light of where lays the red line that divides something from a service tool and makes it an addiction. We are aware that there were times when we used doves to send letters, than we used postal services to send greeting cards; afterwards computers were introduced which at the beginning where only calculation devices and later became a tool form anything; while the introduction of mobile devices made things even more involving and addicting for the fact that we carry them whenever we go, making it hard to not use them.
\end{abstract}

Keywords: computer devices, social involvement, service, addiction.

\section{INTRODUCTION}

One day I was walking in the street and suddenly looked at the sky to see whether the clouds would bring rain or the would scatter away and the sun will shine. At that moment I heard someone, which was a friend of mine, who told me that there will be rain around three o'clock in the afternoon. I smiled, saluted him and moved on. This moment made remember something from a week earlier, when I needed to know the result of a football game, or the many other times I've read emails or done other things on my laptop or phone. That was the time that I seriously thought about how much we are attached to such devices. But I had a bitter/sweet feeling about the issue, because I was aware that I do my daily and work tasks with them, but was also aware that too much dependance on them makes us a bit lazy, if that's the proper word to use for this. But the seriousness of the issue lays on the usage of such devices from children and teenagers; they are way more prone to be addicted to such things as social networking and various other messaging and video services.

\section{MASTER OR SLAVE}

All of us use a mobile phone to communicate with our loved ones. We talk with them, send messages and it all seems so natural. But after a while we begin to acknowledge the fact that at times, such devices can make us addicted to them, and instead of us using them according to our needs, we start to act according to the 'rule of the 
device'. We like to browse the Internet, find information that we need, a lot of times also information that we don't need; after a while we start playing games and in the end we begin wasting our time.

Considering the fact that digital devices have become an integral part of our everyday lives, "people are spending a considerable amount of time using it for various purposes including social networking and gaming. The overdependence on such media could be, in some cases, attributed to emotional escapism such as escaping from stress, depression and other real-life problems.' (Cham et al. (2019, p. 1) we should mention that the term Digital Addiction (DA)has been described as 'a high degree of behavioral dependence on software products. 'Kirshner, Karpinski (2010) Griffiths (2005), mentions six symptoms for digital addiction, those being: salience: that is expressed when the use of digital devices becomes a crucial activity for the one who uses it; mood modification: when digital devices are used as some kind of coping strategy for certain users; tolerance: when there is an increase in the usage of digital devices over time; withdrawal symptoms: when the user behaves in an unpleasant way , especially when he or she is unable to interact with digital devices in the way he or she wishes; conflict: when we have intrapersonal issues caused by the usage of digital devices; and, finally, relapse: when a user quickly falls back to his or her old usage habits, specifically after a certain period of usage abstinence.

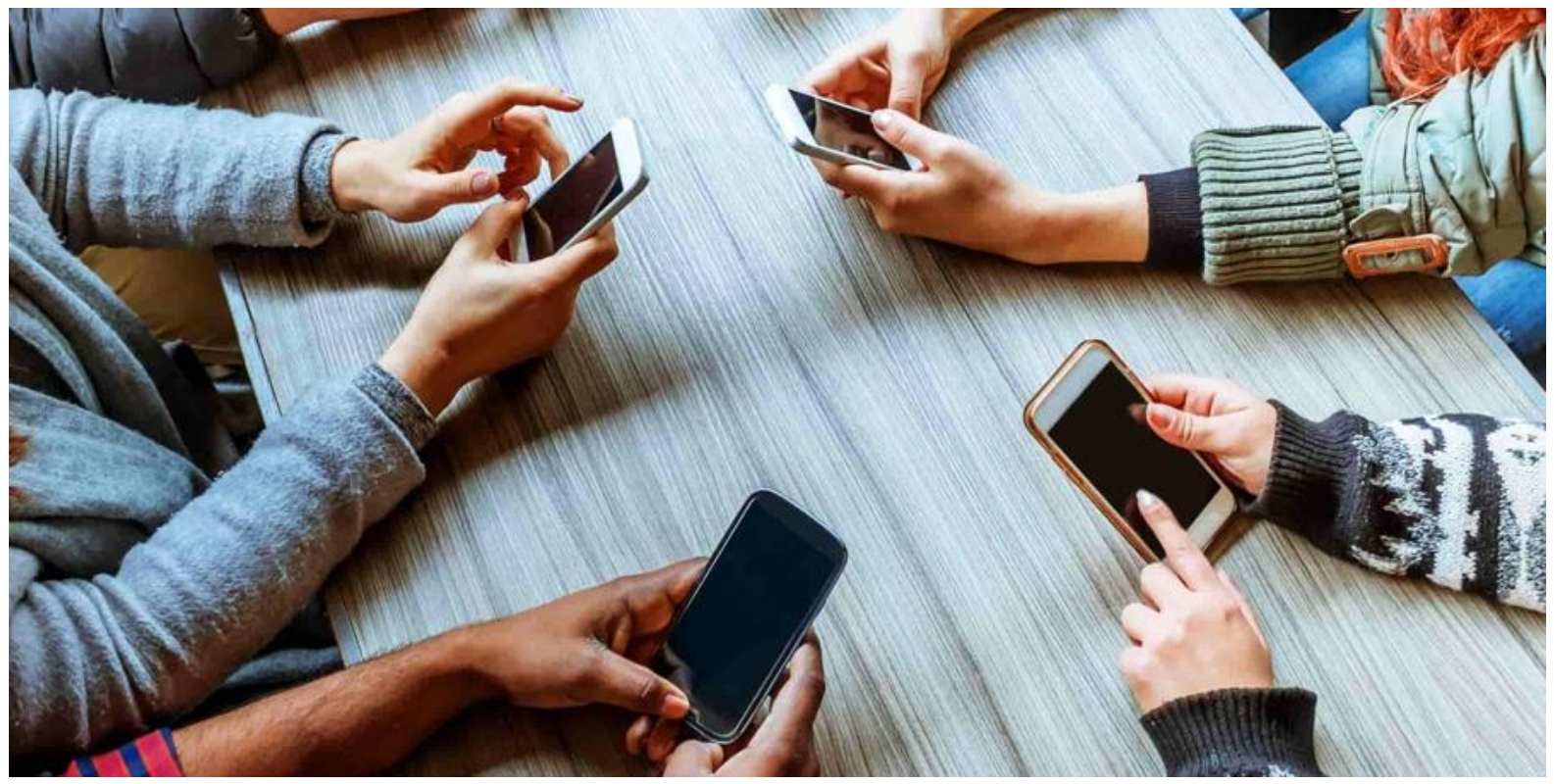

\section{FINDING THE MIDDLE GROUND}

Being addicted to something doesn't actually mean we should avoid it by any cost, the thing is that we need to find a middle ground where we will be able to control the way and time we use such devices.

This kind of addiction is becoming a highly recognized problem on a global scale. Data provided by Cham et al (2019, p. 2), suggest that: ' $40 \%$ of adults in the UK look at their phone within five minutes of waking up, and $37 \%$ of adults check their phones five minutes before turning lights out. Also, the UK tops the list of the prevalence of internet addiction among university students at $18.3 \%$ followed by Poland at $16.2 \%$ and Taiwan at $15.1 \%$.' While according to Muller et al. (2014), there was a $2.1 \%$ internet addiction rate in the German population obtained from general population data.

In other words, digital devices addiction is present on a global scale, and finding the golden middle is of utmost importance. 


\section{WHAT THE FUTURE HOLDS?}

If we take into consideration science fiction literature, robotic machines will rule the world making us slaves on their way to achieve that. The reality is far away from such dystopian view of the world, the real issue with which we need to deal on daily basis is reading emails, writing our homework essays, chatting with our relatives and other similar tasks, which although a first may seem simple, still, their routine nature can make us deeply attached to them.

There is one very important thing that we must emphasize on this regard, and that is the fact that digital devices are becoming more advanced with each iteration, and we must ask the unavoidable question of whether we will become even more addicted to such devices or we will be able to draw a red line of where fun ends and our lives become more attached to the world around? It is hard to answer a question like this because its answer depends on many things which are not in our command, therefore we will let the future bring the answer in its own right.

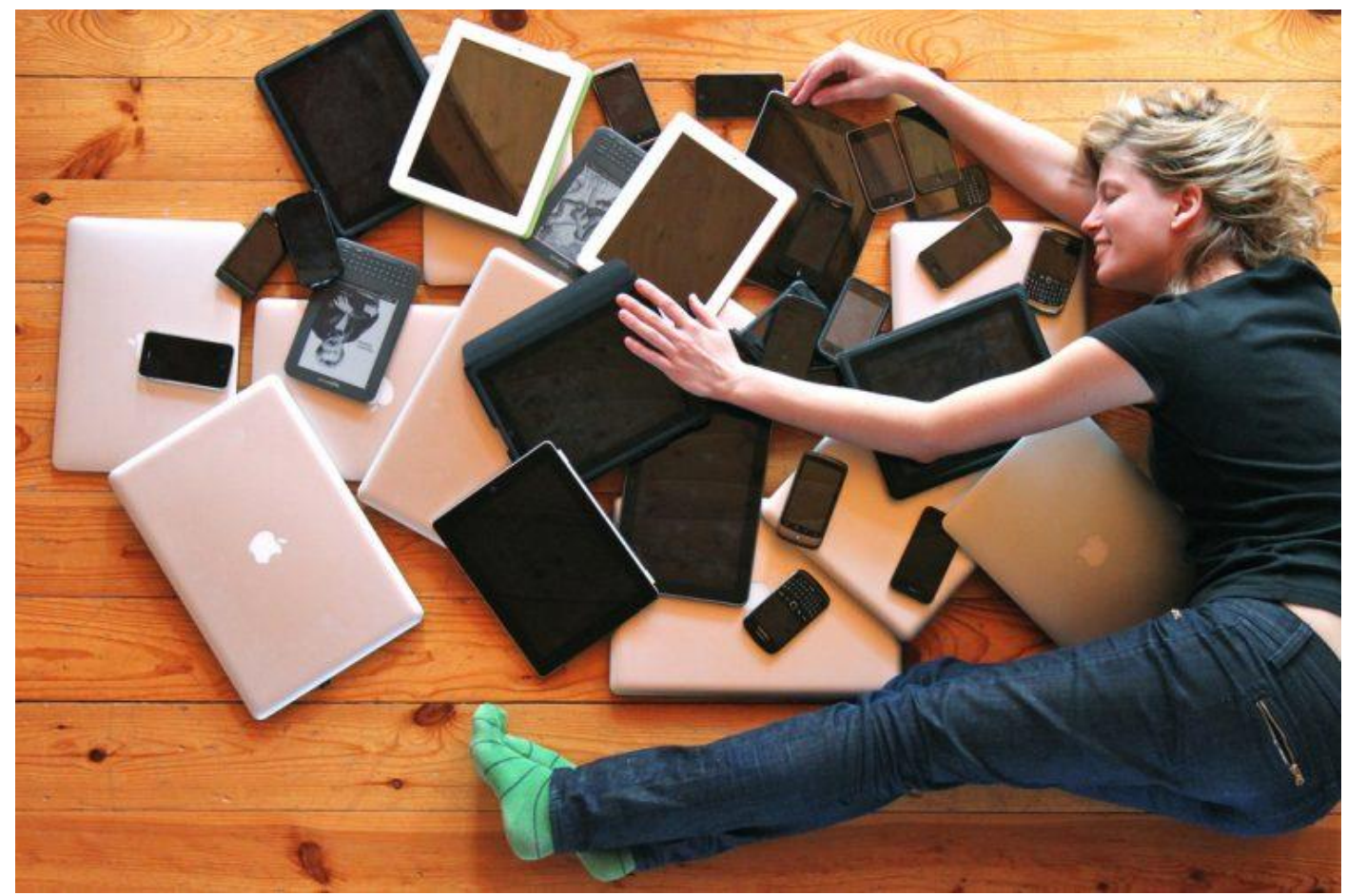

\section{CONCLUSION}

Addiction to digital devices is not something that you only see on a movie screen or in some newspaper, it is a serious occurrence that quite possible is present in all our homes; it may be our children that are addicted to such devices, maybe our spouses, or even more interestingly, we, ourselves, may have such an addiction. Therefore, we should take this issue very seriously, especially when we consider that those same devices are used on daily basis to do things that are a must, meaning that it is not easy to get away from those tools. We may have a store where we need to calculate our daily, weekly, monthly or yearly sales; we may have a thesis to write for our school assignment; we may need to write a book; we may need to send some highly important message to someone. All these services cannot be overstated and information technologies are the basis for such services, and as we previously mentioned, the line between a device to turn from a service tool into addiction is very thin. So, when next you have an urge to browse the web from your mobile phone, be strong and, instead, why not take a walk on the beautiful green hills.

\section{References and Bibliography}

Abel, J.P., Buff, C.L., Burr, S.A.: Social media and the fear of missing out: scale development and assessment. J. Bus. Econ. Res. 14(1), 33 (2016) 
Algashami, A., Cham, S., Vuillier, L., Stefanidis, A., Phalp, K., Ali, R.: Conceptualising gamification risks to teamwork within enterprise. In: IFIP Working Conference on the Practice of Enterprise Modelling, pp. 105-120. Springer, Cham (2018)

Algashami, A., Shahri, A., McAlaney, J., Taylor, J., Phalp, K., Ali, R.: Strategies and design principles to minimize negative side-effects of digital motivation on teamwork. In: International Conference on Persuasive Technology, pp. 267-278. Springer (2017)

Alrobai, A., McAlaney, J., Dogan, H., Phalp, K., Ali, R.: Exploring the requirements and design of persuasive intervention technology to combat digital addiction. In: HCI, vol. 9856, LNCS, pp. 130-150 (2016)

Cham, S., (et. Al.) (2019). Digital Addiction: Negative Life Experiences and Potential for Technology-Assisted Solutions. WorldCIST'19 2019, AISC 931, pp. 921-931, 2019.

Griffiths, M.D.: A "components" model of addiction within a biopsychosocial framework. J. Subst. Use 10, 191-197 (2005)

Kirschner, P.A., Karpinski, A.C.: Facebook® and academic performance. Comput. Hum. Behav. 26(6), 1237-1245 (2010)

Kuss, D.J., Griffiths, M.D., Binder, J.F.: Internet addiction in students: prevalence and risk factors. Comput. Hum. Behav. 29, 959-966 (2013)

Lino, A., Rocha, A., Sizo, A.: Virtual teaching and learning environments: automatic evaluation with artificial neural networks. Cluster Comput. 1-11 (2017)

Muller, K.W., Glaesmer, H., Brähler, E., Wolfling, K., Beutel, M.: Prevalence of internet addiction in the general population: results from a german population-based survey. Behav. Inf. Technol. 37(7), 1-10 (2014)

Nikbin, D., Iranmanesh, M., Foroughi, R. (2020). Personality traits, psychological well-being, Facebook addiction, health and performance: testing their relationships. BEHAVIOUR \& INFORMATION TECHNOLOGY https://doi.org/10.1080/0144929X.2020.1722749 